\title{
FORMALDEHYDE FORMATION FROM TRIMETHYLAMINE OXIDE BY THE ACTION OF PYLORIC CAECA OF COD*
}

\author{
Keishi Amano and Kinjiro Yamada** \\ (Received June 12, 1964)
}

In the preceding papers ${ }^{1 / 2) 3}$, the writers described the facts that formaldehyde was naturally existing in the muscle tissue and organs of gadoid fish, and the freshness of the fish should have some relation to the formation and the amount of FA. SoudAN ${ }^{45)}$ reported the presence of FA in the products prepared from the fish which normally contained TMO. She considered the formation of FA by a dissociation of TMO. VAISEY ${ }^{6}$ proved a production of FA from TMO in vitro test, by reductive action of cysteine in the presence of ferrous ion or haemoglobin. In his experiment, VAISEY found DMA as the one of the decomposition products from TMO. BEATTY and CoLlins $^{7 /}$ detected no DMA in the press juice of cod, obtained by filtering it through Seitz Filter. They assumed bacterial action might be associated with in the formation of DMA, because of the absence of DMA in the bacteria-free press juice.

From a brief review of these works hitherto published, it seems to be hard to conclude whether the formation of formaldehyde is carried out by chemical or biological process. The present report was prepared to add a new finding for the discussion of this problem.

\section{Experimentals and Results}

\section{Experiment 1. Dissociation of TMO}

This experiment was intended, by using a purified TMO, to see whether TMO decomposed into DMA and FA under normal conditions in such a way that was suggested by SoudaN ${ }^{4}$.

Purification of TMO: $10 \mathrm{gm}$ of TMO of reagent grade were dissolved in $100 \mathrm{ml}$ of ethanol and condensed by gentle heating in a procelain basin on water bath. Then, the concentrate was cooled down to $-20 \mathrm{C}$ until the crystals deposited. Thus, collected crystals were recrystalized repeatedly from a mixture of acetone and ethanol (1:1). After purification, crystals were dried at $80 \mathrm{C}$ and tested for melting point. A reading of $96 \mathrm{C}$ showed that the crystals being pure TMO $2 \mathrm{H}_{2} \mathrm{O}$.

Effect of $p H$ on the dissociation of TMO: A series of $0.075 \mathrm{~m}$ solution of TMO, varying in $\mathrm{pH}$ from 4.3 to 8.0 , was prepared by adding McIlvaine buffer solution of respective $\mathrm{pH}$ value in equal quantity to $0.15 \mathrm{M}$ TMO solution. A $2 \mathrm{ml}$ portion of

* Contribution B. 406, from the Tokai Regional Fisheries Research Laboratory (Tsukishima, Chuo-ku, Tokyo, Japan)



Abbreviations used: TMO (trimethylamine oxide), TMA (trimethylamine), DMA (dimethylamine), FA (formaldehyde), and TCA (trichloroacetic acid) 
$0.075 \mathrm{M}$ TMO with different $\mathrm{pH}$ was tested for FA by Rimini's and phloroglucin reagent, immediately after the preparation of the solution and after a storage of 24 hours at $30 \mathrm{C}$. Both reactions found negative for the presence of $\mathrm{FA}$, under the conditions mentioned above.

Effect of temperature upon the dissociation of TMO: A series of $10 \mathrm{ml}$ of $0.075 \mathrm{M}$ TMO, adjusted to $\mathrm{pH} 6.6$ by adding McIlvaine buffer, was examined as to the temperature effect on the dissociation of TMO. The temperature range tested was between $20 \mathrm{C}$ and $70 \mathrm{C}$ with an interval of $10 \mathrm{C}$. After standing for 24 hours at each temperature, the solution was withdrawn and tested for FA, but no sign of the presence of FA was observed by both Rimini's and phloroglucin reagent.

\section{Experiment 2. Storage test of carp muscle to which TMO was mixed}

If TMO continues to follow the dissociation in the muscles of fish or crustaceans in the presence of many reactive radicals which may combine with $F A$, as it was described by Soudan, the decomposition of TMO should take place even when TMO is deliberately added to the muscle tissue which is normally lacking TMO, such as carp. So, carp muscle was chosen to examine whether the tissue was able to produce FA and DMA from TMO. A live female carp with a length of $48 \mathrm{~cm}$ and weight of $2.0 \mathrm{~kg}$, was killed by decapitation without any struggle after taking out of water, and the muscle was comminuted by a mincer without the removal of dark meat portion. To $20 \mathrm{gm}$ of the chopped meat, added $50 \mathrm{ml}$ of Mcllvaine buffer solution varying in $\mathrm{pH}$ from 3.9 to 7.6. To each buffered carp preparation, $10 \mathrm{ml}$ of $0.15 \mathrm{M} \mathrm{TMO}, 3 \mathrm{ml}$ of toluene, and $1 \mathrm{ml}$ of chloroform were consecutively added and the whole solution was kept at $30 \mathrm{C}$ for 24 hours. A control muscle preparation, which was not buffered, showed $\mathrm{pH}$ of 6.1. At the termination of incubation period, 20\% TCA solution was added and the TCA extract was subjected to the determinations of TMA, DMA and FA by the methods described in the previous paper. There was found none of FA and DMA in the mixtures after the incubation test, however, a very small amount of TMA was detected in a suspension buffered between $\mathrm{pH} 6.1$ and 7.6. The amount of TMA nitrogen was not greater than $0.5 \mathrm{mg}$ in $100 \mathrm{gm}$ of the muscle.

\section{Experiment 3. Decomposition of TMO by pyloric caeca from cod}

As it was mentioned in the first report of this series of papers, the content of FA was higher in pyloric caeca than any other tissue from cod. In this connection, a possibility of FA production by pyloric caeca was examined in the following experiment.

About $400 \mathrm{gm}$ of pyloric caeca were gathered from twelve fresh cods caught from the Essa Strait, Japan Sea, on February 17 and 18, 1962. These tissues were comminuted and treated in the following three ways.

Sample A: $100 \mathrm{gm}$ of pyloric caeca plus $300 \mathrm{ml}$ of water.

Sample B: To the suspension prepared in the same way as A, added $10 \mathrm{ml}$ of toluene and $5 \mathrm{ml}$ of chloroform. 
Sample C: $100 \mathrm{gm}$ of pyloric caeca were mixed with $250 \mathrm{ml}$ of water and $50 \mathrm{ml}$ of $0.15 \mathrm{M}$ TMO solution, then added by $10 \mathrm{ml}$ of toluene and $5 \mathrm{ml}$ of chloroform.

The above three sets of the suspension were stood in an incubator at $20 \mathrm{C}$. At every 10 hours, a $20 \mathrm{gm}$ portion was weighed out and added $20 \mathrm{ml}$ of $20 \%$ TCA reagent. Determination of DMA and FA was conducted on the TCA extract thus prepared, by the methods described in the foregoing papers. But, the determination of TMA* was carried out by Conway's microdiffusion method, while TMO was determined in the same way after the reduction of it to TMA by Devarda's alloy. Results obtained are shown in the Figures from 1 to 3 .

In the sample A, TMA appeared with a lapse of time and reached the amount of $10.4 \mathrm{mg} \%$ at the onset of spoilage, though there was found no TMO at the beginning of storage. On the other hand, the increase in DMA started earlier and reached an equilibrium by 10 hours of storage. As it is quite obvious from Fig. 1, FA was already near to $4 \mathrm{mg} \%$ of content at 0 hour of the experiment and increased



Fig. 1. Formation of formaldehyde and volatile amines in cod pyloric caeca suspension.

Arrows indicate the symptom of spoilage in odor.

* TMA values obtained by Conway's method were rather higher, possibly due to the diffusion of DMA, which might not be fixed by the addition of formaldehyde used in this determination procedure. 




Fig. 2. Formation of formaldehyde and volatile amines in cod pyloric caeca suspension added with toluene and chloroform

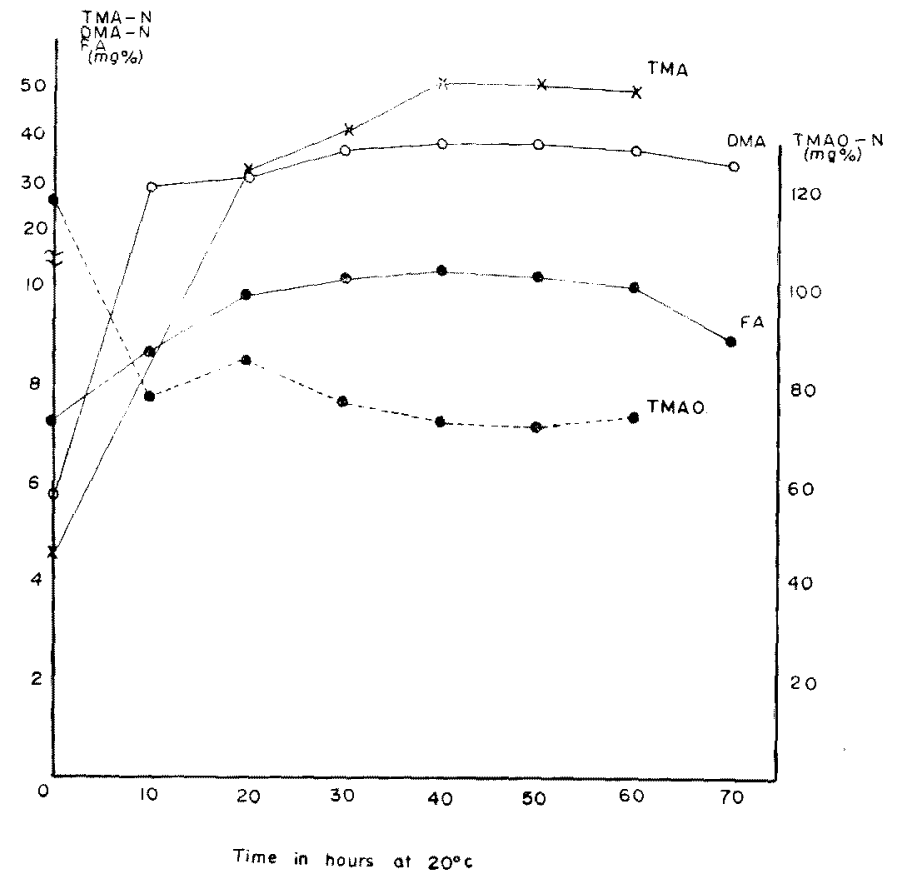

Fig. 3. Formation of formaldehyde and volatile amines in cod pyloric caeca suspension added with trimethylamine oxide, toluene and chloroform.

in parallel with DMA till 10 hours, when it stopped increasing, then showed decrease gradually in the later part of storage.

In the sample B, to which antiseptics were mixed, the increase in both FA and DMA was observed in early stage of incubation and the pattern of the changes in these two components looked similar throughout the storage period. A reason for 
slight decrease of FA after 10 hours might be explained by a suppressed state of bacterial dehydrogenation of FA owing to the use of antiseptics. TMA developed also in this case, as it was seen in Sample A, though none of TMO was detected at the beginning. But, it is of interesting that TMO has also been increasing after 30 hours towards the end of incubation period.

The sample $\mathrm{C}$, which represented a mixture of pyloric caeca of cod and TMO of intended addition, showed a remarkable development of FA and DMA under the inhibition of bacterial growth. The amount of DMA found in sample $C$ was approximately twenty times higher than that of sample $B$, while FA in sample $C$ was twice as much as sample B. And, the decrease of TMO was rapid at first 10 hours of standing, which corresponded to the increase of DMA or FA. A production of TMA, which showed a steady increase from start of storage, might be suggesting another type of enzymatic action.

\section{Discussion}

According to the paper by SounAN ${ }^{51}$, TMO is an aldimine of FA and DMA and the reaction of the following scheme goes leftwards under acidic condition or in the presence of certain catalyst that is able to transfer electrons from one to another.

$$
\text { aldehyde }+ \text { amine } \rightleftarrows \text { aldimine }
$$

But, as our experiment 1 indicated, TMO was not so labile as suggested by Soudan. TMO showed no sign of dissociation in a $\mathrm{pH}$ range between 4.3 and 8.0 , and also by the raise of temperature up to $70 \mathrm{C}$. However, our results would not include the findings of FA formation from TMO in the presence of hydrosulfite, the use of which is normally practiced to bleach meat color of fish by the industry.

The fact that of no development of FA from TMO by carp muscle, seems to make Soudan's suggestion difficult, because it may not be reasonable to assume that carp muscle is poor in the radicals which Soudan has proposed a principle to combine with aldehyde group and consequently to accelerate a spontaneous breakdown of TMO. The cause of FA production in certain kind of fishery products, such as herring and shrimp, should be followed from different angle.

SHEWAN ${ }^{8)}$ reported that DMA was hardly existing in the flesh of dog fish(Scyllium canescens) though his paper did not deal with FA problem. The writers confirmed that no FA was detected in shark and squid meat which were believed to be rich in TMO content. Recently, HAYASHI and colleagues ${ }^{9)}$ described no DMA was present in spoiled meat of squid and white clam, when they tried to identify volatile amines in these molluscs by gas chromatography.

In the light of these findings, the possibility of spontaneous production of FA by a process of dissociation of TMO is likely less feasible.

VAISEY $^{6)}$ made it successful to convert TMO into FA and DMA in vitro by the action of cysteine in the presence of ferrous ion or haemoglobin. However, the 
concentration of cysteine or ferrous ion employed by VAISEY was rather higher than that naturally contained in cod and related species. In addition, it is hard to presume that the content of cysteine or even ferrous ion is larger enough to set forth the VAISEY's system than those in shark or carp meat which is not capable to produce FA and DMA. Another fact of rich content of FA in pyloric caeca, bile bladder, and spleen, which are regularly poor in TMO content, will present difficulty to support the process of FA formation described by VAISEY so far cod species are concerned.

After a brief review of the foregoing work, including data presented here, the question on the natural occurrence of $\mathrm{FA}$ in cod varieties may be explained by supposing the occurrence of particular enzyme that is capable to generate FA as well as DMA by splitting TMO. Possibly, shark muscle may be lacking of this enzyme, regardless high content of TMO in these fish.

But, this hypothesis will meet difficulty with the fact observed by BEATTY and CoLlins $^{7}$, where they found no DMA in a press juice of cod flesh, prepared by the filtration through Seitz Filter. This fact may imply a bacterial participation in DMA formation and consequently FA formation, too. However, they never made a determination of $\mathrm{FA}$ in their experiment.

As indicated above, Fig. 3 is showing a remarkable production of FA in aseptically maintained pyloric caeca, to which TMO has been added. So far that experiment went, there could not be existing the propagation of microorganisms, except some numbers of microflora grown before the test got started. Thus, the estimation of FA forming enzyme in the pyloric caeca may be more plausible.

In case of sample $A$ of the experiment 3 , increase in the amount of TMA was fairly obvious, even though the absence of TMO in pyloric caeca was certain. It will indicate the occurrence of any other precursor than TMO in pyloric caeca, because a trace amount of TMO would not be taken account for a production of $10 \mathrm{mg}$ of TMA nitrogen. Furthermore, a gradual increase in the content of TMO observed in the sample B(Fig. 2) under aseptic storage of pyloric caeca will offer another interest of biochemistry of gadoid group. Further work should be directed on this line, too.

\section{Summary}

A fact, that pyloric caeca of cod is capable to convert TMO into FA and DMA under normal condition, has been presented. This transformation of FA or DMA may be carried out by specific enzyme present in the pyloric caeca.

A possible occurrence of the precursor to generate TMA other than TMO and of the precursor to form TMO in the pyloric caeca was also suggested.

\section{References}

1) Amano, K., Yamada, K. and Bito, M.: Bull. Jap. Soc. Sci. Fish., 29, 695 (1963).

2) Amano, K., Yamada, K. and Bito, M.: ibid., 29, 860 (1963). 
3) Amano, K. and Yamada, K.: ibid., 30, 430 (1964),

4) Soudan, F.: Rev. Trav. Inst. Pêches marit, 23, 203 (1959).

5) SoUdAN, F.: Presented Paper at FAO International Conference on Fish in Nutrition, Washington, D. C., Sept. 19-27 (1961).

6) VaiseY, E. B.: Canadian J. Biochem. Physiol., 34, 1085 (1956).

7) BEAtTy, S. A. and Collins, V. K.: J. Fish. Res. Bd. Canada, 5, 32 (1940).

8) Shewan, J. M.: Ann. Rept. Food Invest. Bd., p. 79 (1939).

9) Hayashi, M., Unemoto, T., UChida, R. and MiYaki, K.: Ann. Rept. Inst. Food Microbiol., Chiba Univ., 15, 39 (1963). 